\title{
Blucher
}

Blucher Proceedings

Cuba e Brasil no Século XXI (CBS21)

A Construção do Conhecimento

\section{Lógica das Relações para a Cooperação Internacional}

\author{
Dra. Mônica Baptista Pereira Estrázulas ${ }^{1}$
}

\section{Introdução}

A organização das reuniões Cuba e Brasil no Século XXI (CBS21), em La Habana / Cuba (em 2012) e em Recife, Olinda e Maceió/Brasil (em 2013), pautou-se pelo desafio da contribuição acadêmica à proposição de projetos seminais e estratégicos, com envolvimento das duas nações amigas em sua transição à sociedade do conhecimento.

Os projetos, que seriam concebidos e desenvolvidos por meio de iniciativas conjuntas no âmbito da cooperação internacional, estariam inspirados nos compromissos de satisfazer necessidades básicas das populações cubana e brasileira, bem como desenvolver e apoiar sua capacidade de organização/reorganização para promover melhorias em seu nível de vida, sem prejuízos às coletividades e entornos locais, regionais e globais. Sublinhou-se a convicção de que os projetos constituir-se-iam como meios para que as presentes e futuras gerações dos dois países pudessem tomar decisões alicerçadas em princípios éticos fundamentais à construção e à manutenção de uma sociedade internacional mais justa, sustentável e pacífica.

É necessário compreender que o desafio, em sua totalidade, passa a implicar iniciativas situadas no contexto da cooperação, em si, como modo operandis do trabalho a ser desenvolvido pelas duas nações, de tal forma que deixa implícito

\footnotetext{
${ }^{1}$ Colégio de Aplicação - CAP, Universidade Federal do Rio Grande do Sul - UFRGS, Porto Alegre, Brasil. E-mail: monicpoa@gmail.com.
} 
um agir cooperativo (quiçá solidário) a ser incorporado às etapas de concepção, implementação, avaliação e ajustes das ações. Trata-se de um desafio à cooperação internacional para o qual a visão sistêmica é determinante ao alcance de objetivos em comum.

Assim, simultaneamente à discussão sobre a proposição de projetos envolvendo especialistas e colaboradores de centros de investigação, tecnologia e inovação nas diferentes áreas do conhecimento, é preciso atentar para os mecanismos das relações que caracterizam trocas entre individuos e entre coletividades, e que são aplicáveis a colaboradores, grupos de pesquisadores, instituições ou empresas responsáveis por toda a atividade produtiva (indústria, comércio e serviços; estatais, governamentais ou privadas), de um país ou entre países.

Impõe-se destacar aquí que, do ponto de vista da sóciocognição humana, os mecanismos constitutivos da lógica das ações e operações de pensamento subjazem ao estabelecimento e à manutenção de parcerias de trabalho entre indivíduos e entre coletividades. No presente caso, o objetivo de inovar processos de produção e comercialização de bens ou prestação de serviços de ambos os países implicará relações de trocas entre indivíduos, entre centros de geração de novos conhecimentos, e entre esses e os sistemas governamentais ou empresariais.

O que pretendemos é chamar atenção para conhecimentos relevantes na área da sociocognição, que incidem sobre o funcionamento das relações de trocas entre indivíduos e entre coletividades, e que operam na coexistência de equilíbrios e desequilíbrios capazes de garantir ou colocar em risco a conservação dos acordos estabelecidos entre as partes envolvidas, produzindo-se (ou não) as condições para o êxito dos empreendimentos.

Tendo em vista oferecer uma contribuição aos propósitos do trabalho conjunto entre Cuba e Brasil, e inspirados em objetivos construídos nas reuniões CBS21 que precedem o presente artigo, tematizaremos as relações de trocas que se engendram entre indivíduos, ou entre as coletividades em geral, mediante a explicitação de mecanismos sóciocognitivos envolvidos nas mesmas. Posteriormente, caracterizaremos as relações cooperativas e solidárias que, em contraste com as relações egocêntricas, conformistas e de coação, são as que efetivamente podem contribuir para as transformações intelectuais e morais indispensáveis ao homem do século XXI, ao torná-lo consciente de seu papel ativo na construção do conhecimento e na implementação de ações relevantes para o benefício e a harmonia planetária.

O referencial utilizado consiste fundamentalmente no sistema teórico de Jean Piaget, em estudos publicados na área (Freitas, 1997) e em estudos empíricos realizados pela autora (Estrázulas, 2004) sobre temas relacionados ao desenvolvimento intelectual e moral, lógica das relações, noções de justiça, cooperação e solidariedade. 


\section{Mecanismos das Trocas entre Indivíduos e Coletividades}

Para descrever o mecanismo das trocas entre dois indivíduos identificados por a e a', Piaget (1965/1973) formulou duas equações qualitativas:

$$
\begin{aligned}
& \text { Equação I: }\left(\mathrm{ra}=\mathrm{sa}^{\prime}\right)+\left(\mathrm{sa}^{\prime}=\mathrm{ta}^{\prime}\right)+\left(\mathrm{ta}^{\prime}=\mathrm{va}\right)=(\mathrm{ra}=\mathrm{va}) \\
& \text { Equação II: }\left(\mathrm{va}=\mathrm{ta}^{\prime}\right)+\left(\mathrm{ta}^{\prime}=\mathrm{ra}^{\prime}\right)+\left(\mathrm{ra}^{\prime}=\mathrm{sa}\right)=(\mathrm{va}=\mathrm{sa})
\end{aligned}
$$

Os termos da Equação I e da Equação II significam: (r) uma ação/iniciativa, (s) uma avaliação, (t) uma obrigação gerada pela avaliação, (v) um valor atribuído a uma ação ou iniciativa no contexto de uma troca entre a e a'. Podemos dizer que o conjunto das duas equações (I e II) representa um ciclo de ações e operações constituído pelas trocas estabelecidas pelos indivíduos (a) e (a') entre si, ou pelas coletividades.

No plano das ações ou das elaborações intelectuais (pensamento), as trocas efetivadas produzem as igualdades expressas no interior dos parênteses; essas igualdades indicam a existência de um equilíbrio cuja origem se apoia em equivalências existentes entre: ra : uma iniciativa do indivíduo (a); sa': uma avaliação elaborada por (a') relativamente à iniciativa ra; ta': uma obrigação de (a') gerada pela avaliação sa'; va: um valor virtual em favor de (a), gerado pela obrigação de a'; ra': uma ação de (a') que incorpora a obrigação ta'; sa: uma avaliação elaborada por (a) relativamente à ação ra'.

$\mathrm{Na}$ Equação I, o equilíbrio das trocas interindividuais conduz a uma igualdade entre os dois lados da equação, ou seja, o somatório das três primeiras equivalências $\left(\mathrm{ra}=\mathrm{sa}^{\prime}\right)+\left(\mathrm{sa}^{\prime}=\mathrm{ta}^{\prime}\right)+\left(\mathrm{ta}{ }^{\prime}=\mathrm{va}\right)$ é igual a quarta equivalência $(\mathrm{ra}=\mathrm{va}) . \mathrm{O}$ mesmo raciocínio se aplica à Equação II. A presença dessas equivalências no interior dos parênteses evidencia que as ações realizadas em comum foram consideradas de mesmo valor pelos interessados, (a) e (a'). Por exemplo, em $\left(\mathrm{ra}=\mathrm{sa}^{\prime}\right)$, podemos supor que (a) tomou a iniciativa de enviar livros para (a') e essa ação satisfez (a'); nesse caso, a iniciativa de uma pessoa equivale à satisfação da outra. Na sequência do mesmo exemplo, em (sa' = ta'), a satisfação de (a') implica uma obrigação para com (a), ou seja, de alguma maneira (a') se sente interiormente grata pelo envio dos livros e interessada em retribuir a satisfação; em (ta' = va), a obrigação de (a') equivale a um valor (va) que poderá ser executado a favor de (a), de imediato (trocas atuais) ou no futuro (trocas não-atuais), ou seja, uma retribuição de (a') para (a). O que significa a igualdade entre os dois lados da Equação I? Significa que a soma das equivalências no primeiro lado da equação tende à conservação dos valores envolvidos nas trocas, isto é, à iniciativa (ra) foi atribuido um valor virtual (va) que, no futuro ( na Equação II), deverá corresponder exatamente à satisfação de quem tomou a iniciativa (a). Em resumo, o conjunto de ações e operações que compõem a Equação I, quando há equilíbrio nas trocas, produz a 
equivalência $(\mathrm{ra}=\mathrm{va})$ pois a iniciativa de $(\mathrm{a})$ se encontra virtualmente compensada pela valorização (va). Se de imediato não há uma retribuição, esta é presumida a partir da satisfação gerada em (sa'). É por essa razão que há uma sequência necessária de ações e operações expressa na Equação II. Nessa sequência, (a') terá a oportunidade de retribuir, ou seja, de executar o valor virtual (va) e assim cumprir com a obrigação (ta'). De fato, é o que ocorre quando (a') incorpora os valores virtuais em jogo na ação/iniciativa (ra'). No nosso exemplo, (a') poderia prestar algum auxílio espontâneo, que fosse importante na avaliação de (a).

Da mesma maneira, a toda primeira iniciativa ra de (a) deverá corresponder à possibilidade de uma primeira iniciativa de (a'). Esta alternância de papéis torna-se indispensável à reciprocidade nas trocas e se traduz pelo mesmo conjunto de equações (I e II), porém com a inversão dos índices, de modo que as ações correspondam aos indivíduos que as executam. As Equações I e II (bis), segundo a denominação original de Piaget, expressam a nova situação assim:

$$
\begin{aligned}
& \text { Equação I (bis) : }\left(\mathrm{ra}^{\prime}=\mathrm{sa}\right)+(\mathrm{sa}=\mathrm{ta})+\left(\mathrm{ta}=\mathrm{va}{ }^{\prime}\right)=\left(\mathrm{ra}^{\prime}=\mathrm{va}{ }^{\prime}\right) \\
& \text { Equação II }(\mathrm{bis}):\left(\mathrm{va}^{\prime}=\mathrm{ta}\right)+(\mathrm{ta}=\mathrm{ra})+\left(\mathrm{ra}=\mathrm{sa}^{\prime}\right)=\left(\mathrm{va}=\mathrm{sa}^{\prime}\right)
\end{aligned}
$$

O que muda com a inversão dos papéis entre (a) e (a’)? Nas Equações I e II, quando qualquer um dos parceiros dá início às trocas, o outro tem a possibilidade de avaliar a ação/iniciativa do primeiro. Então, o que muda é a possibilidade de haver alternância de iniciativas e avaliações, ou seja, há a presença da reciprocidade.

Normalmente, nas relações sociais, os adultos têm a prerrogativa de manifestar a idéia inicial ou dar início a uma ação (e assim também os chefes com relação aos subalternos, os mais fortes com relação aos mais fracos...), porém nem sempre o mesmo acontece quando a iniciativa se esboça da parte da criança, dos subalternos ou dos mais fracos...A fixação dos papéis, nesse caso, evidencia uma ausência de reciprocidade e, portanto, uma assimetria que tende a produzir desequilíbrio nas trocas. Se, no primeiro conjunto de equações o indivíduo (a) dá inicio a uma ação que é avaliada por (a'), no segundo conjunto, quem toma a iniciativa é (a') e as avaliações são produzidas por (a), ou seja, o avaliador passa a ser avaliado e o avaliado passa a avaliador. Assim, no segundo conjunto de equações (I e II, bis) inverte-se o problema pois (a') toma a iniciativa e não simplesmente reage às propostas de ação de (a); (a') se descobre na perspectiva de quem produz escolhas, ou lança a primeira idéia e submete-a a avaliação de (a). Por seu turno, o indivíduo (a), agora no papel de avaliador da iniciativa de (a'), é instado a deslocar seu ponto de vista até o de um outro (a') que, por sua livre escolha, tomou a iniciativa e propos algo.

O raciocínio anterior tem em vista obter o equilíbrio das trocas, explicitado nas igualdades entre todos os termos nas quatro equações (I e II; I bis e II bis). 
Trata-se de um modelo para situações nas quais há cooperação com reciprocidade total; os demais casos demandam a introdução de desigualdades no interior das equações, como reflexo das inconsistências existentes em nosso agir cotidiano.

\section{Lógica das Relações e Coordenação Normativa dos Valores morais}

Em seu Ensaio sobre a Teoria dos Valores Qualitativos em Sociologia Estática ("sincrônica"), Piaget (1965/1973) propõe o reconhecimento das interações entre indivíduos, notadamente aquelas que os modificam de modo durável, como "fatos sociais" e, também, de toda a sociedade como um sistema de obrigações (regras) e trocas (valores), expressos por símbolos convencionais (sinais). Enquanto a validade das normas (regras) depende de sua história ou de evolução no tempo, os valores de troca só dependem do equilíbrio entre fenômenos simultâneos e, por isso, os primeiros se apresentam como fenômenos diacrônicos e os últimos têm significação do ponto de vista sincrônico.

Os valores sociais de troca, concebidos como qualitativos, englobam todos os serviços prestados (iniciativas), ou os derivados deles mas que se distinguem dos valores econômicos, uma vez que esses últimos submetem-se a uma métrica e são, portanto, quantitativos. Ao tratar dos valores qualitativos das trocas sociais, à exceção das econômicas, Piaget $(1965 / 1973$, p.116) sugeriu uma “... axiomática de ordem logística, isto é, a axiomática das 'classes' e das 'relações' e não a dos números (...) para exprimir em termos precisos o mecanismo de troca dos valores qualitativos...".

As ações, trabalhos e serviços prestados pelos indivíduos, sejam atuais (imediatos) ou virtuais (no tempo), são passíveis de avaliação e comparação mediante relações que constituem as mais diferentes escalas de valores (políticas, religiosas, estéticas, ...), provenientes de diferentes fontes (interesses individuais, valores coletivos impostos, ...), de acordo com finalidades a atingir e meios empregados para tal. Tomando uma escala de valores como "um sistema de relações assimétricas a qual corresponde uma sucessão de termos de valor crescente A,B, C, ..." (Piaget, 1965/1973, p. 117), podemos dizer que: A tem menor valor que B, B menor que $\mathrm{C}, \ldots$ Se $\mathrm{A}$ constitui um meio para a finalidade $\mathrm{B}$, este último é um meio para a finalidade C...e assim em diante. Se A1, A2, A3, ... forem substituíveis entre si como meios que conduzem à finalidade $\mathrm{B}$, então dizemos que têm valor equivalente.

Sabemos que um mesmo indivíduo conhece e emprega várias escalas ao produzir avaliações e comparações (satisfações) entre ações e trabalhos (renúncias), atuais ou virtuais, realizados por outros ou por ele mesmo. No conjunto, entre vários indivíduos constatamos a co-existência de escalas de valores empregadas na contínua valorização recíproca das ações de uns e de outros. Assim, as ações podem vir a ser consideradas proveitosas, prejudiciais ou indiferentes, havendo 
valorização positiva quando há satisfação, negativa quando ocorre insatisfação, e ainda, nenhum acréscimo ou nenhuma diminuição de valor quando o proveito (ou o prejuízo) é considerado nulo.

Vejamos: a) o indivíduo a presta um serviço com troca imediata de um serviço realizado pelo outro (a'), por exemplo, um cientista envia parecer sobre um capítulo de livro para um colega e recebe como agradecimento a cópia do livro publicado; b) o indivíduo a presta um serviço que é reconhecido por a' embora sem troca de serviço imediato deste àquele; por exemplo, quando uma liderança intervém a favor de uma coletividade e o benefício alcançado o torna credor ou alvo de prestígio junto à mesma; c) o indivíduo a presta um serviço que resta indiferente para a'; por exemplo, quando à ação de um benfeitor que não resulta em dívida de reconhecimento por parte dos beneficiados.

Como podemos verificar, a renúncia atual, isto é, um serviço prestado por um indivíduo (a) pode engendrar a satisfação atual do outro (a'), ou retribuição imediata, tanto quanto pode constituir uma satisfação virtual para (a), uma vez que oportunamente (a') poderá oferecer retribuição. É interessante ressaltar que, mesmo no caso da retribuição imediata, em função de que houve satisfação por parte daquele que foi beneficiado, o mesmo resulta agradecido e, segundo Piaget, daí decorre um compromisso de (a') para com (a), uma obrigação denominada renúncia virtual. Inversamente, nos exemplos referidos, nada impede, por outro lado, que os resultados do serviço prestado pelo indivíduo (a) sejam valorizados negativamente por (a'). Da mesma forma, pode ocorrer o caso de uma renúncia atual ficar sem uma renúncia futura de valor equivalente à satisfação atual (ou mesmo virtual) produzida.

Ao aplicarmos regras de correspondência aos valores trocados entre a e a', podemos assumir a hipótese de que a e a' estão de acordo com relação à escala de valores e assim verificar como se comportam as equações lógicas I e II, formuladas por Piaget, nas quais os significados dos termos empregados correspondem a: (ra) $=$ ação de a, (s a') = satisfação de a', (ta') = obrigação resultante da satisfação a', (va) = valorização de a por a'.

No equilíbrio das equivalências (equivalência geral), resulta a Equação I: ( $\mathrm{ra}=$ $\left.\mathrm{sa}^{\prime}\right)+\left(\mathrm{sa}^{\prime}=\mathrm{ta}^{\prime}\right)+\left(\mathrm{ta}^{\prime}=\mathrm{va}\right)=(\mathrm{va}=\mathrm{ra})$, na qual a é valorizado por a' na mesma proporção do serviço prestado, tratando-se por isso de uma equivalência simples. Como não há nada que obrigue os envolvidos a respeitar essas equivalências, concluimos que somente a existência de normas, sejam morais ou jurídicas, pode assegurar o equilíbrio da Equação I.

$\mathrm{Na}$ ausência de normas que garantam essas equivalências, ou seja, quando apenas os sentimentos e interesses individuais espontâneos têm lugar (é o caso das crianças e o de muitos adultos), encontramos situações para as quais não se confirma o equilíbrio das trocas. 
Diz-se que a trabalha com prejuízo quando : a) ra $>$ s a', pois o esforço dispendido por a não satisfaz a', o que implica (rąva) e, como consequência, ou a se submete à avaliação e renuncia à ação, ou retifica sua escala de valores, muda de atividade, ou ainda, diferentemente, não valoriza o seu avaliador (a') e retoma a ação segundo seus próprios valores; b) sa'> ta', uma vez que a' esqueceu (não conservou) a obrigação gerada em função da satisfação produzida pela ação de a, o que conduz a (rąva);

Diz-se que a trabalha com vantagem quando : a) ra $<$ sa', pois a avaliação positiva supera o esforço despendido e conduz para (va $>$ ra); a aprovação social leva a persistir na ação; b) sa'< ta', graças a uma superavaliação dos reais serviços realizados (dívida de gratidão), o que resulta em (ra<va).

Se ressaltamos até aqui as valorizações alcançadas por a quando valores reais são trocados por valores virtuais, faz-se necessário indagar sobre a realização futura desses valores virtuais. Como a converterá seus créditos (va)? Como as aprovações, gratidões, reputação e autoridade poderão reverter sob a forma de serviços de a' para a?

Ao considerarmos o equilíbrio das equivalências, temos que examinar a Equação II $:\left(\mathrm{va}=\mathrm{ta}^{\prime}\right)+\left(\mathrm{ta}=\mathrm{ra}^{\prime}\right)+\left(\mathrm{ra}^{\prime}=\mathrm{sa}^{\prime}\right)=(\mathrm{sa}=\mathrm{va})$, na qual a' reconhece a dívida (ta') contraída na mesma medida do crédito (va) e, como consequência, realiza a ação (ra') que salda a dívida porque produz a satisfação (sa) do crédito. Entretanto, poderá ocorrer a não satisfação dos créditos, o que implicará a inexistência de algumas equivalências na Equação II e, portanto, um desequilíbrio nas trocas sociais.

Piaget assinala que dificilmente na vida em sociedade reclamamos a integralidade de nossos créditos ou realizamos a totalidade de nossas dívidas, caracterizandose a circulação dos valores sociais por assentar-se "...num vasto crédito perpetuamente mantido..." (Piaget, 1965/1973, p.126), em função dos esquecimentos, por exemplo, e que somente cessam por ocasião das revoluções, quando uma generalizada e brusca desvalorização concorre para a ruptura entre todas as escalas de valores.

Como já vimos, Piaget (1965/1973) considera que o equilíbrio social repousa na dinâmica das trocas e não na natureza dos sentimentos que constituem seu conteúdo subjetivo. Em razão disso, propõe um estudo das condições de equilíbrio das trocas de valores via abordagem exclusiva das leis que regem aquela dinâmica, qualquer que seja sua subjetividade, sem que necessitemos subordinar as equivalências ao conteúdo dos valores em si. Para exemplificar, Piaget afirma que as valorizações relativas à magia no interior de uma tribo obedecerão às mesmas leis gerais de equilíbrio das trocas, sem que tenhamos necessidade de questionar seus significados.

Reconhecemos, em sintonia com o autor, que as trocas entre indivíduos cons- 
tituem mecanismo essencialmente coletivo, no qual os valores trocados tornam-se dependentes de um sistema total de relações entre dois ou vários sujeitos, por um lado, e os objetos, por outro (Piaget, 1965/1973). Para o equilíbrio ou a conservação de uma coletividade são duas as condições: a) no mínimo, uma escala comum de valores e b) benefícios recíprocos entre seus membros.

O fato inicial é a valorização recíproca entre os que realizam trocas, ou seja, entre membros de uma mesma classe de co-valorizantes. Nesse sentido, o equilíbrio ou a conservação de uma coletividade submete-se às condições de equilíbrio nas trocas qualitativas uma vez que a primeira condição supõe uma linguagem e um sistema de noções ou significados comuns estabelecendo pontes entre escalas diferentes; enquanto a segunda, desdobra-se na conservação de acordos firmados durante as trocas e na reciprocidade de pensamento entre parceiros. Dado que o equilíbrio das trocas depende de valorizações qualitativas entre os que permutam valores, e não sendo rara a existência de alterações nos valores ou mesmo a desvalorização de trabalhos já realizados, as coletividades se valem de dispositivos para a conservação dos valores traduzidos por obrigações, sejam de ordem moral ou jurídica. Assim, nas trocas entre co-valorizantes podem ocorrer tanto o equilíbrio exato, quanto o equilíbrio obtido por valorizações ou desvalorizações recíprocas, e ainda, inversamente, entre co-valorizantes podem ocorrer trocas com desequilíbrios.

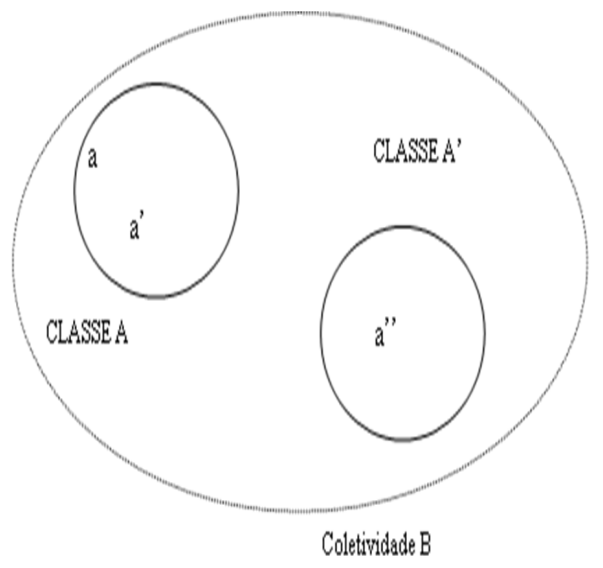

Figura 1: Classes co-valorizantes A e A' e coletividade B.

Na Figura 1, as trocas entre os indivíduos (a e a') de uma mesma classe de co-valorizantes A, ou entre indivíduos das classes A e A', condicionam o equilíbrio da coletividade B. Quando há valorização recíproca entre indivíduos de A e A', a coletividade $\mathrm{B}$ é dita naturalmente estável. Ao contrário, nas desvalorizações recíprocas, a coletividade $B$ subsiste artificialmente e às custas de normas jurídicas. Nesses casos, a manutenção das relações se dá quase que exclusivamente por um 
fator de obrigação ou conveniência, tendo em vista que as trocas se estabelecem sem satisfações de parte a parte, viabilizam-se em função de artificialidades e condutas interessadas.

Quando sobrevêm desequilíbrios nas trocas, podem surgir crises sociais, com ou sem ruptura da escala de valores. Desse modo, as crises sociais podem variar desde a insatisfação atual entre parceiros (a e a') ou classes (A e A') de uma coletividade (B), até a perda de valores anteriormente capitalizados.

A insatisfação atual entre indivíduos a e a' (ou mesmo entre as classes A e A' de uma coletividade B) ocorre quando a' ou A' não têm mais as mesmas necessidades (quantitativas ou qualitativas), enquanto a oferta de serviços de a permanece igual ou aumenta. O descompasso ocasiona uma crise cuja superação se dá por um reajuste entre oferta e procura dos serviços. Nesse tipo de crise social, a desigualdade ( $\mathrm{ra}>$ sa') revela a insatisfação de a' em relação aos serviços de a.

A perda de valores capitalizados por a' ou A' decorre da utilização dos créditos qualitativos sem a devida reposição ou reconstituição dos mesmos mediante novos serviços prestados. Com isso, surgem esquecimentos ou descontentamentos e, consequentemente, desvalorizações. A superação dessa crise exige oferta ou prestação de serviços que resultem em novas satisfações e, portanto, novos créditos.

Tanto a insatisfação atual quanto a perda de valores capitalizados ocorrem sem ruptura da escala comum porque a desvalorização nos dois casos se apoia nos mesmos valores reconhecidos por ocasião da constituição dos créditos. O desgaste produzido pela conjugação das duas crises anteriores, entretanto, coloca sob ameaça o equilíbrio das trocas e pode levar à ruptura da escala comum de valores existente entre os indivíduos a e a' ou entre as classes A e A' (coletividade B). Dessa forma, as trocas baseadas na antiga escala comum resultam impossíveis porque o que era valorizado já não o é mais e as trocas não se efetivam por falta de uma base comum. A superação dessa crise só é possível com a construção de uma nova escala comum de valores, o que demanda esforços múltiplos que devem levar em conta a dependência das trocas qualitativas em relação ao sistema de normas. Se é verdadeiro, como propõe Piaget (1965/1973, p.138), que

“... toda sociedade apresenta um conjunto de operações gerais de conservação dos valores cujo papel é assegurar o equilíbrio não mais pelo balanço automático da troca espontânea mas graças a uma série de obrigações cada vez mais precisas segundo são de ordem moral ou jurídica ..."

então, essas mesmas obrigações ou regras constituem-se como coordenação dos pontos de vista em jogo, no interior das trocas. Assim, cumpre examinar sob quais condições se dá a transição da troca simples (espontânea) à troca normativa que requer a reciprocidade de ordem moral. A Tabela 1, a seguir, sintetiza elementos para a compreensão da coordenação normativa dos valores a partir da passagem das 
- Tabela 1. Coordenação normativa dos Valores quautativos

\begin{tabular}{|c|c|c|}
\hline $\begin{array}{c}\text { COORDENAÇAo } \\
\text { NORMATIVA DOS } \\
\text { VALORES QUALTITITOS }\end{array}$ & $\begin{array}{l}\text { TROCA ESPONTÅNEA } \\
\text { (SIMPIES, ATUAL) }\end{array}$ & $\begin{array}{l}\text { TROCA NORMATIVA } \\
\text { (NO TEMPO) }\end{array}$ \\
\hline controle & $\begin{array}{l}\text { Sistema de simples } \\
\text { percepções }\end{array}$ & $\begin{array}{l}\text { Sistema de operações normativas de ordem lógica } \\
\text { (raciocínio) }\end{array}$ \\
\hline reciprocidade & Vivida, intuitiva & Durável, normativa \\
\hline finalidade & $\begin{array}{l}\text { a age (ra) em vista do seu } \\
\text { sucesso (va); a satisfação } \\
\text { do outro (sa') é meio para a } \\
\text { satisfação própria; }\end{array}$ & $\begin{array}{l}\text { a age visando a satisfação do outro onde (s a') não é } \\
\text { meio, é fim ; fonte da obrigação é o respeito à pessoa }\end{array}$ \\
\hline $\begin{array}{l}\text { método operatório } \\
\text { de } \\
\text { conservação } \\
\text { dos valores } \\
\text { (meios) }\end{array}$ & $\begin{array}{l}\text { Não há normatividade: não } \\
\text { há valores virtuais em jogo; } \\
\text { há percepção imediata dos } \\
\text { valores; Caráter } \\
\text { interessado das açóes; a e } \\
\text { a' utilizam cada qual a sua } \\
\text { própria escala de valores } \\
\text { para avaliar os resultados } \\
\text { da ação do outro }\end{array}$ & 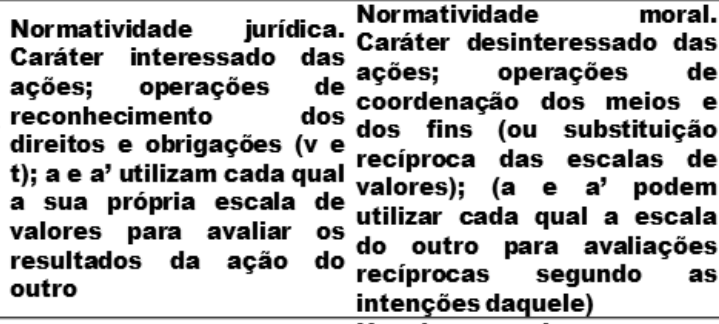 \\
\hline $\begin{array}{l}\text { condições de } \\
\text { equilíbrio }\end{array}$ & $\begin{array}{l}\text { Compensação dos esforços } \\
\text { e proveitos, serviços e } \\
\text { benefícios }\end{array}$ & $\begin{array}{l}\text { o reconhecimento de um Um dos parceiros conserva } \\
\text { direito es valores do outro, segundo } \\
\text { obrigação, a execução das a escala desse outro; a } \\
\text { obrigações a a satisfação tende à satisfação indefinida } \\
\text { do direito } \\
\text { de a'; e a' reconhece os } \\
\text { valores morais de (a) }\end{array}$ \\
\hline
\end{tabular}

Figura 2: Coordenação Normativa dos Valores Qualitativos.

$\mathrm{Na}$ Figura 2, denominamos troca simples ou espontânea aquela cujos valores podem ser diretamente controlados pelos interessados, segundo um sistema de percepções, ou representações não normativas. A troca normativa, também denominada troca durável, foge ao controle ou percepção atual, e exige a intervenção de normas estabilizadoras, ou seja, da reversibilidade operatória. Enquanto a troca simples implica somente uma reciprocidade vivida sem que os valores se tornem duráveis além do evento da troca, a reciprocidade normativa caracteriza a troca durável justamente porque, garantida pela reversibilidade operatória, gera obrigação sobre débitos anteriormente contraídos e que não pertencem mais aos quadros de controle ou percepções atuais.

O conjunto de operações que tende à conservação dos valores, nas trocas descritas pelas Equações I e II, constitui um sistema de normas morais ou jurídicas. Sabemos que o equilíbrio das trocas pode sofrer alterações em função da instabilidade dos valores, tendo em vista que estão em jogo os valores intra-individuais 
(atribuídos à própria ação) e os interindividuais (atribuídos às outras pessoas, suas ações ou serviços). Para assegurar a conservação obrigatória dos valores trocados, necessitamos de um sistema de operações de ordem formal que garanta aos valores presentes a durabilidade das relações e condições de equivalência. Esse sistema de operações pode ser estudado segundo métodos axiomáticos ou lógicos.

Dois são os métodos operatórios de conservação de valores qualitativos: um, constituído pelas normas jurídicas, transforma os valores de troca virtuais ( $\mathrm{v}$ e t) em direitos e obrigações mediante operações de reconhecimento; outro, constituído pela moral, realiza avaliações recíprocas de caráter desinteressado mediante operações de coordenação e substituição dos meios e dos fins.

Nosso interesse recai sobre as condições morais de conservação dos valores, cujo caráter desinteressado das ações deve contemplar: a) a satisfação indefinida do outro, evidenciada quando a é capaz de agir não mais segundo um ponto de vista de seu interesse, senão em função da escala de valores de a' com o fim exclusivo de alcançar a satisfação desse; b) a avaliação segundo a intenção do outro, evidenciada quando a' não se detém nos resultados da ação de a mas na valorização de suas intenções, ou seja, de sua escala de valores.

As duas condições anteriores repercutem nas Equações I e II como segue: (ra = sa'), sendo a iniciativa ra avaliada por a' segundo as intenções de a, enquanto a satisfação sa', avaliada segundo a escala de a' constitui um fim para a; ta' e va adquirem significados que decorrem da ausência de dever de a' retribuir um serviço e, em seu lugar, surgem: uma aprovação moral, ou seja, a é aprovado moralmente por a', o que significa que a escala dos valores normativos de a é reconhecida por a' e, ainda, a obrigação ta' se transforma numa obrigação moral que a' contrai por si mesmo e significa agir segundo a escala normativa de a .

Diferentemente do que ocorria na troca simples ou mesmo na troca durável de caráter interessado, o equilíbrio normativo de reciprocidade moral é alcançado quando um dos parceiros conserva os valores do outro, segundo a escala desse outro: a tendendo à satisfação indefinida de a' e, o outro, a', reconhecendo o valor moral de a . De onde provém, entretanto, a obrigação ta', através da qual a' aprova moralmente a? Vem do sentimento de respeito, da estima e aprovação de a' com relação a a . A repercussão dessa obrigação moral na Equação II ocorre quando a' age em ra' de acordo com esse sentimento de respeito, ou seja, segundo ta, ou de acordo com a escala de valores de a. É a satisfação moral de a (s a) em função da intenção de a' em ra' que finaliza um ciclo de reciprocidade normativa na Equação II.

Quando a troca se dá apenas através da submissão à norma de reciprocidade de um dos parceiros, há desigualdade e não mais equivalência nas trocas. Nesse caso, quando apenas um dos parceiros é recíproco e respeita a norma, o que sucede? Há ainda a necessidade de respeito à norma que rege as trocas mesmo quando nosso 
parceiro não o faz? De fato, para aquele que já conserva a obrigação, a norma permanece, e independe da reação do outro. Quem, nesse caso, reconhecerá o valor da ação executada segundo à norma? O autor da ação, isto é, aquele que conserva a obrigação é quem reconhece seu próprio valor e o faz na perspectiva de uma satisfação interior, da consciência mesma. O valor va independe da reação de a', isto é, da valorização do parceiro a' e exatamente nisso reside o seu mérito moral.

O caráter moral da ação do indivíduo a só pode ser compreendido segundo a dimensão diacrônica que intervém a partir de obrigações anteriores, contraídas por a em relação a a' mesmo, ou em relação a outros parceiros e que lhe impõem alguns valores a serem respeitados devido a uma conservação no tempo, quer em função do respeito que continuam a lhe inspirar, quer pelo caráter obrigatório da norma em função da história. Isso tudo porque a hipótese aqui adotada, tal como o fez Piaget, é a da norma como resultante de um equilíbrio que resiste no tempo, como obrigação que assegura o equilíbrio entre as trocas atuais e todas as anteriores. É o respeito pela pessoa e não à norma em si, conforme Piaget e Bovet, que engendra a obrigação, e não o inverso. O respeito à pessoa resulta da valorização que alguém atribui a outrem, ou seja, advém do respeito que um indivíduo sente por outro porque o valoriza como tal.

Como compreender o respeito que alguém sente por outro que ainda não o respeita, ou por outro cujo respeito não é recíproco? Contribui de alguma forma esse respeito "unilateral" para que, nas interações conosco, aquele que ainda não nos respeita venha a experimentar ou sentir o respeito mútuo? Se "...o respeito não é, como os demais, um sentimento recebido por alguma influência, pois se trata de um sentimento ¡sui generis ¿ oriundo de um conceito da razão..." (Freitas, 1997, p.78), conviver com alguém que nos respeita contribuirá para que respeitemos a essa pessoa a partir do respeito à lei moral que ela representa? Nesse caso, se a obrigação moral tem origem no sentimento interindividual do respeito que se desenvolve numa criança em função das interações com os demais, o que conduz essa criança a respeitar alguém? Ou a fazê-la deixar de julgar a ação do outro de acordo com a sua satisfação pessoal e passar a fazê-lo segundo a intenção desse outro? O que a obriga internamente a fazer isso, a agir segundo a reciprocidade normativa de ordem moral? Sendo a obrigação gerada pelo respeito à pessoa, o indivíduo que respeita não pode agir de modo a contradizer esse sentimento, então é a necessidade lógica de não-contradição que, ao exigir coerência interna, se apóia na descentração que une a situação atual a uma outra anterior e garante a conservação dos valores. Assim, ao afirmarmos que a' respeita a, queremos dizer que a' se coloca no ponto de vista de a e livremente se torna capaz de experimentar sua escala de valores. Quando há reciprocidade na substituição dos meios e dos fins, cada qual visa a satisfação do outro como única finalidade de sua própria ação, 
então se diz que a mesma expressa o respeito mútuo existente entre a e a' ou a valorização recíproca de dois indivíduos, cujo produto nada mais é do que a reciprocidade normativa. Essa reciprocidade normativa só é possível como fruto de um desenvolvimento da lógica, e aqui convém recordar que a mesma se impõe "...como necessidade mas a título de equilíbrio final para o qual tendem necessariamente as coordenações práticas e mentais e não como necessidade de partida..." (Piaget, 1965/1973, p.173). O argumento sustenta nosso interesse em abordá-lo pois se trata de compreender os mecanismos envolvidos no desenvolvimento da lógica das relações subjacentes à coordenação normativa dos valores morais - substrato da educação individual e interindividual, informal (familiar) e formal (escolar) - como meios para a aprendizagem da solidariedade e da justiça necessárias à finalidade da educação para a cooperação internacional (Piaget, 1931/1998).

É necessário assegurar às pessoas, desde a infância, uma educação feita de oportunidades para o exercício das avaliações e críticas (aspecto moral) e o das pesquisas e verificações (aspecto intelectual), ou seja, uma educação da razão como condição necessária à autonomia, que nada mais é senão a educação para a liberdade oriunda da cooperação.

O desenvolvimento individual, que vai do egocentrismo intelectual e da heteronomia moral até a lógica das relações, ou em outras palavras, desde a indiferenciação dos pontos de vista até a conquista de sua perspectivação e autonomia moral, pode ser observado segundo a presença do sentimento de respeito de um indivíduo por outro. Sublinhamos que os dois tipos de respeito, unilateral e mútuo, geram obrigações de natureza diferente, como a obediência e o dever moral, que correspondem, respectivamente, à valorização não recíproca entre indivíduos e à atribuição de valor equivalente entre os mesmos (Piaget, 1931/1998) .

Estudos empíricos nos levaram a compreender que toda a valorização recíproca evidenciará momentaneamente um desequilíbrio nas trocas, sem que o contrário seja verdadeiro, uma vez que nem todo o desequilíbrio significa a presença de valorizações mútuas (Estrázulas, 2004). Ao observarmos o comportamento da Equação I, veremos que o elemento responsável por uma diferença nas equivalências é justamente o valor virtual (va ou va'), pois devido às satisfações, em lugar da igualdade $($ va $=$ ra $)$, momentaneamente se obtém a desigualdade (va $>$ ra). Entretanto, o que significa tal desequilíbrio? Significa que as interações interindividuais com valorização recíproca produzem um saldo positivo no valor virtual (va) pois a satisfação (s a') sempre ultrapassa o esforço dispendido (ra). Assim, se considerarmos as iniciativas de a e a', verificaremos que as desigualdades entre ação e valor virtual (com satisfação atual ou virtual) resultam sempre, de parte a parte, em proveito mútuo. O desequilíbrio é apenas momentâneo porque no somatório final, devido à reciprocidade, igualam-se novamente as valorizações e, portanto, recuperam-se as equivalências. É nesse sentido que podemos afirmar a estabilidade 
de uma classe ou coletividade formada por individuos cujas interações produzem valorizações recíprocas. A visibilidade das valorizações recíprocas somente se satisfaz com equivalências produzidas nas quatro equações (I e II, I e II (bis)). É, portanto, necessário identificar ações e operações de a e de a' que evidenciem um sistema móvel, portanto, em condições de se desequilibrar e reequilibrar devido à estabilidade da estrutura operatória.

Em se tratando do equilíbrio nas trocas de valores, nada é mais instável, afirmava Piaget (1973). Essa afirmação parece contrariar o nosso senso comum, e nem poderia ser diferente, porque estamos mais facilmente inclinados a entender um equilíbrio estático do que um equilíbrio dinâmico. O equilíbrio exato nas trocas de valores é instável porque se refere justamente a uma igualdade ou equivalência apenas momentâneas, seja porque as satisfações a respeito de algo podem se transformar em insatisfações a qualquer momento (sem antídoto ao abrigo de qualquer racionalidade), seja porque os valores conquistados se degradam sem cessar, “...à mercê das desvalorizações imprevisíveis de detalhe ou de conjunto..." (Piaget, 1973, p.138). Se não fossem as regras de conservação morais e jurídicas, qualquer equilíbrio seria impossível, inclusive o estático, porque a dinâmica das trocas dependeria de conteúdos variáveis a todo o momento. Sendo assim, a possibilidade de qualquer conservação deve ser compreendida à luz da constituição dos dispositivos de conservação de valores, os quais nos conduzem das trocas espontâneas à normatividade, como veremos mais adiante, por meio de um sistema de operações lógicas, ou de pura equivalência. Sendo de natureza lógica, como explicar a instabilidade dos equilíbrios exatos se as equações aparecem equilibradas? Onde reconhecê-los nas trocas de valores? Ora, nas trocas atuais, sob controle direto e percetivo dos interessados, não constitui problema maior acompanhar o mecanismo. O equilíbrio exato, entretanto, seria insuficiente para compensar a degradação dessas trocas apoiadas simplesmente em conteúdos móveis. É nesse sentido que, se uma coletividade mantiver apenas trocas equilibradas exatas, subsistirá somente enquanto os valores concorrentes não a desequilibrarem, conforme assinalou Piaget (1973). Os desequilíbrios, no entanto, longe de constituírem exclusivamente uma ameaça à viabilidade de uma coletividade (crises sociais) e levá-la à desorganização total, podem engendrar reequilibrações que exijam a intervenção de normas estabilizadoras típicas de sistemas operatórios (a reversibilidade). Essa reequilibração sinalizaria o desenvolvimento da lógica das relações nos indivíduos e nas coletividades.

\section{Cooperação Segundo o Modelo Axiomático de Jean Piaget}

Como já sabemos, as quatro Equações Qualitativas I, II, (I e II bis) exprimem correspondências entre valores trocados por co-valorizantes sob a forma de esquemas logísticos. Quando as correspondências entre valores de troca no interior das quatro equações qualitativas estão equilibradas, há cooperação. Podemos dizer 
que, se aos esquemas logísticos reunirmos avaliações que contabilizam os proveitos ou prejuízos alcançados nas trocas imediatas ou duráveis, então os serviços prestados e os créditos acumulados serão visualizados em função de renúncias e satisfações relacionadas às ações realizadas, respectivamente.

Nas trocas em que há cooperação, a renúncia atual de (a) corresponde exatamente à satisfação (atual ou virtual) de (a') ; em outras palavras, se a ação de (a) gera benefício para (a'), a ação de (a') gera uma retribuição para (a). Idêntico raciocínio serve para o caso das iniciativas de (a'), em que o beneficiado é (a). Para quem observa as Equações qualitativas I e II, só há equivalências. Entretanto, a rigor, não é o que ocorre. Recordemos que para Piaget $(1973$, p.126) (...) a circulação dos valores sociais repousa, pelo contrário, num vasto crédito (...) uma vez que nunca reclamamos integralmente o que nos é devido, nem conseguimos pagar totalmente nossas dívidas. Por outro lado, como bem assinalou Piaget, mesmo que tenhamos retribuído o benefício, para o beneficiado resulta também uma dívida de reconhecimento. Seria esse reconhecimento capaz de assegurar a continuidade das trocas futuras, segundo uma renúncia virtual que venha a garantir a execução dos créditos da outra parte? Vejamos.

Num ciclo cooperativo os proveitos mútuos se compensam, pois mesmo havendo uma variação positiva devido aos acréscimos de valor reconhecidos nas avaliações de cada parceiro, no conjunto, não há excesso, nem falta, porque não sendo quantificáveis, a rigor, os valores qualitativos estão equilibrados pela valorização recíproca ou satisfação mútua (atual ou virtual). Nesse caso, a resposta à questão anterior seria negativa, ou seja, sob o ponto de vista dos proveitos não haveria diferença a justificar a continuidade das trocas após a quitação dos valores ao final de um ciclo cooperativo. Por outro lado, a dívida de reconhecimento só pode decorrer de um respeito mútuo. Sendo assim, ao final de um ciclo cooperativo as dívidas de reconhecimento de parte a parte conduzem, novamente, a uma quitação mútua, sem desequilíbrios que justifiquem uma reequilibração via continuidade das trocas.

Porém, nem toda a troca equilibrada, no sentido do equilíbrio das ações realizadas, advém do respeito mútuo, pois se é verdade que o equilíbrio das trocas decorre do cumprimento de obrigações e toda a obrigação tem origem num respeito, também é verdade que nem todo o respeito é mútuo. Logo, nas trocas nas quais o equilíbrio é obtido mesmo quando um dos parceiros ainda é regido pela moral da obediência, é improvável que o respeito (unilateral) seja a origem de uma dívida de reconhecimento pois a reciprocidade seria obtida às expensas do medo ou do cumprimento estrito à lei ou à autoridade que a representa. Ora, se ainda não há respeito mútuo por parte de um dos parceiros (mesmo que não existam adversidades), de onde provém a possibilidade do equilíbrio obtido?

Afirmamos até aqui que a cooperação é o equilíbrio ou a equivalência entre valores de troca, ápice de uma coordenação alcançada nas trocas entre iguais, 
ou entre os que se conduzem como iguais, dado que se entendem como de valor equivalente. Então, quando um dos parceiros ainda não reconhece a legitimidade do ponto de vista do outro, produz-se além de um desequilíbrio, um impasse, pois os valores desse não se comunicam com os do outro. Desse modo, não há como deixar de retornar à questão anterior: como explicar o equilíbrio obtido em trocas nas quais um dos parceiros ainda não é recíproco? Essa questão permanece em aberto, até aqui.

\section{Reinterpretação do Modelo de Cooperação de Jean Piaget}

Vejamos, mais detidamente, o que ocorre no caso das trocas em que não há reciprocidade. Nas trocas em que há valorização não-recíproca, a renúncia atual de (a) não corresponde exatamente à satisfação (atual ou virtual) de (a'); em outras palavras, se a ação de (a) gera benefício para (a'), a ação de (a') nem sempre gera uma retribuição para (a). O raciocínio, entretanto, não se aplica às iniciativas de (a') que beneficiam (a) pois esse permanece recíproco a (a') a despeito da não retribuição. Para quem observa as Equações qualitativas I e II, coexistem equivalências e desigualdades, uma vez que (a') não é recíproco nas trocas que estabelece com (a). Haveria alguma possibilidade da ação recíproca de um dos parceiros gerar uma dívida de reconhecimento no outro que ainda não é recíproco? Aparentemente não, caso consideremos a dívida de reconhecimento dependente de uma obrigação sequer gerada, mesmo quando há benefício. Entretanto, não foi o que observamos em várias oportunidades, em estudos empíricos desenvolvidos ao longo de 6 anos.

Onde estaria a brecha capaz de gerar o respeito, que por sua vez geraria a obrigação e a dívida de reconhecimento, mesmo quando as trocas de valor ainda não são recíprocas? Nossa hipótese se baseia na sustentação de uma ação de caráter desinteressado por parte do benfeitor (a) em relação ao beneficiado (a'), a qual chamamos solidariedade. Essa sustentação da ação constitui uma reciprocidade de ordem moral, uma vez que a satisfação do parceiro não recíproco (a') constitui uma finalidade e não mais um meio para quem é solidário (a). O ato é moral pois, durante as trocas, o parceiro solidário (a) se desloca para o ponto de vista do outro (a') e conduz sua ação de caráter desinteressado, levando-o em conta. Por se tratar de uma ação na qual o parceiro não-solidário é capaz de reconhecer valores de troca segundo a sua própria escala, advém uma satisfação inicial que o obriga a reconhecer as intenções do benfeitor. Reconhecer as intenções significa avaliar a ação segundo a escala de valores do autor da ação. Esse reconhecimento rudimentar é viabilizado porque o ato solidário funciona como um canal de comunicação entre as duas escalas, no qual o livre trânsito dos valores de troca está garantido pela ação de caráter desinteressado do parceiro solidário. Desse modo, o beneficiado dispõe de meios para reconhecer os valores morais do benfeitor. Quando a ação 
que visa a satisfação indefinida do outro e a avaliação que reconhece a escala de valores do beneficiado se tornam recíprocas, evidencia-se a coordenação normativa dos valores de caráter moral.

Entendemos que as trocas cooperativas sucedem-se às trocas solidárias pois somente essas são capazes de sustentar a ação recíproca, enquanto um dos parceiros não se sente obrigado à reciprocidade ou à obrigação de consciência. Somente um reconhecimento do valor moral de (a") por (a), ou seja, a aprovação moral que o não-recíproco passa a nutrir pelo parceiro solidário, é capaz de gerar uma obrigação e fazê-lo agir de acordo com ela. Por essa razão, enquanto o beneficiado não lhe é recíproco, o valor da obrigação executada (sa'), ao ser avaliada pelo benfeitor, equivale somente à satisfação moral (ou interior). Piaget (1973) sugere que a origem dessa satisfação interior nós a encontramos em outras ações de caráter desinteressado que continuam a nos inspirar, ali onde anteriormente houve a intervenção do caráter obrigatório da troca normativa. Desse modo, poderíamos dizer que, as ações solidárias não apenas sustentam a passagem do egocentrismo à cooperação, quanto inspiram a realização de novos atos solidários.

Antes de passarmos ao emprego das Equações qualitativas I, II (I e II, bis) convém registrar que, até o momento, não temos notícia de que Piaget as tivesse utilizado para tratar específicamente o problema da solidariedade como propusemos em nosso estudo (Estrázulas, 2004). Piaget (1973) as utilizou, entretanto, na modelização da cooperação e da coordenação normativa de valores morais. Por outro lado, entendemos que se as equações qualitativas representam um esquema axiomático válido para exprimir o mecanismo das trocas qualitativas e se, como afirmou Piaget (1973), não têm nem a intenção ou a possibilidade de suplantar a observação ou a experiência, é plausível que as apresentemos com ajustes, dado que assim estariam contribuindo para preparar novos instrumentos de análise e de comparação como sugeriu o autor. É o que segue.

\section{As Equações Qualitativas Ajustadas e o Ciclo Cooperativo}

Num ciclo cooperativo, as Equações I e II (I e II, bis) que representam o sistema de trocas estão em equilíbrio e evidenciam a reciprocidade das renúncias e satisfações de (a) com relação a (a') e vice-versa:

Eq. I: $\left(\mathrm{ra}=\mathrm{s} \mathrm{a}^{\prime}\right)+\left(\mathrm{sa}^{\prime}=\mathrm{ta}^{\prime}\right)+\left(\mathrm{ta}^{\prime}=\mathrm{va}\right)=(\mathrm{va}=\mathrm{ra})$

Eq. II: $\left(\right.$ va $=$ ta $\left.^{\prime}\right)+\left(\right.$ ta' $\left.^{\prime}=\mathrm{ra}^{\prime}\right)+\left(\mathrm{ra}^{\prime}=\mathrm{s} \mathrm{a}\right)=(\mathrm{s} \mathrm{a}=\mathrm{va})$

Eq. I (bis): $\left(\mathrm{ra}^{\prime}=\mathrm{sa}\right)+(\mathrm{sa}=\mathrm{ta})+\left(\mathrm{ta}=\mathrm{va}^{\prime}\right)=\left(\mathrm{va}^{\prime}=\mathrm{ra}^{\prime}\right)$

Eq. II (bis): $\left(\mathrm{va}^{\prime}=\mathrm{ta}\right)+(\mathrm{ta}=\mathrm{ra})+\left(\mathrm{ra}=\mathrm{sa}^{\prime}\right)=\left(\mathrm{sa}^{\prime}=\mathrm{va}^{\prime}\right)$

Sob o ponto de vista das equações qualitativas, entendemos que o ciclo da cooperação poderia resumir-se às quatro equações com a incluusão de uma dívida 
de reconhecimento, pois Piaget (1973) se refere à mesma como um sentimento de permanecer agradecido, que se conserva mesmo após a execução de uma obrigação:

Equação I

Equação II

Dívida de reconhecimento de a' para com a + renúncia virtual

Equação I (bis)

Equação II (bis)

Dívida de reconhecimento de a para com a’ + renúncia virtual.

A proposta, a seguir, ajusta as equações qualitativas do modelo piagetiano para que exprimam a presença de uma dívida de reconhecimento moral $(\mathrm{Rm})$ e, igualmente, uma renúncia virtual $(\mathrm{Rv})$ que aquela implica, conforme registramos:

$$
\begin{aligned}
& \text { Eq. I: } \left.\left.\left(\mathrm{ra}=\mathrm{sa}^{\prime}\right)+\left(\mathrm{sa}^{\prime}=\mathrm{ta}^{\prime}\right)+\operatorname{Rm}\left(\mathrm{a}^{\prime}\right)\right)+\left(\mathrm{ta}^{\prime}+\mathrm{Rm}\left(\mathrm{a}^{\prime}\right)\right)=\mathrm{va}\right)= \\
& (\mathrm{va}=\mathrm{ra}) \\
& \text { Eq.II: } \left.\left(\mathrm{va}=\mathrm{ta}^{\prime}+\mathrm{Rm}\left(\mathrm{a}^{\prime}\right)\right)+\left(\mathrm{ta}^{\prime}+\mathrm{Rm}\left(\mathrm{a}^{\prime}\right)\right)=\mathrm{ra} \mathrm{r}^{\prime}+\mathrm{Rv}\left(\mathrm{a}^{\prime}\right)\right)+(\mathrm{ra}+ \\
& \left.\left.\operatorname{Rv}\left(\mathrm{a}^{\prime}\right)\right)=\mathrm{sa}\right)=(\mathrm{sa}=\mathrm{va})
\end{aligned}
$$

Na Equação I, temos que a satisfação (sa') de (a') equivale a uma obrigação (ta') relativamente à iniciativa de ( a), acrescida pela dívida de reconhecimento moral Rm(va'), se houver; assim, quando (a') reconhece o caráter desinteressado da ação de (a), atribui valor moral ao parceiro (a) e a dívida se transforma numa obrigação moral de (a') para com (a). Na Equação II, temos que a obrigação moral se converte em renúncia virtual $\left(\operatorname{Rv}\left(a^{\prime}\right)\right)$ e acrescenta valor à execução da obrigação de (a') para com (a).

Nas Equações I e II ( bis), o ciclo cooperativo inverte os índices para indicar a iniciativa do outro parceiro, sem que se alterem as equações, uma vez que a reciprocidade existe e está baseada no respeito mútuo.

\section{As Equações Qualitativas Ajustadas e o Ciclo Solidário}

Num ciclo solidário, em que há o início da sustentação das ações de caráter desinteressado, as Equações I e II ( I e II , bis), que inicialmente representam o sistema de trocas, apresentam desequilíbrios que evidenciam a não reciprocidade das renúncias e satisfações, de acordo com as equações qualitativas originais. Se apenas (a) é recíproco com relação a ( a') temos que:

$$
\begin{aligned}
& \text { Equação I: }\left(\mathrm{ra}>\mathrm{sa}^{\prime}\right)+\left(\mathrm{sa}^{\prime}=\mathrm{ta}^{\prime}\right)+\left(\mathrm{ta}^{\prime}=\mathrm{va}\right)=(\mathrm{va}<\mathrm{ra}) \\
& \text { Equação II }:\left(\mathrm{va}=\mathrm{ta}^{\prime}\right)+\left(\mathrm{ta}^{\prime}>\mathrm{ra}^{\prime}\right)+\left(\mathrm{ra}^{\prime}=\mathrm{sa}\right)=(\mathrm{sa}=\mathrm{va})
\end{aligned}
$$


Equação I (bis): $\left(\mathrm{ra}^{\prime}=\mathrm{sa}\right)+(\mathrm{sa}=\mathrm{ta})+($ ta $=$ va' $)=\left(\mathrm{va}^{\prime}=\mathrm{ra}^{\prime}\right)$

Equação II (bis) : (va' = ta $)+($ ta $=$ ra $)+($ ra $>$ sa' $)=\left(\right.$ sa' $^{\prime}<$ va' $)$

Assim, por exemplo, na Equação I, a iniciativa (ra) de (a) é desvalorizada por (a') e não desencadeia uma obrigação (ta') de valor equivalente ao do investimento inicial; a perspectiva de execução de valores pode inclusive ficar aquém da desvalorização inicial (ta'> ra'); entretanto, na avaliação (s a) de (a) a escala de valores utilizada é a de (a') e com isso, a despeito da não reciprocidade de (a'), o parceiro (a) se mantém recíproco pois reconhece, ele mesmo, uma satisfação moral ao fazer da satisfação de (a') a finalidade de sua ação.

Na Equação II, o valor da obrigação de (a') pode ser ou não conservado (va = ta') ou (va > ta'), tanto quanto o valor da obrigação pode não ser equivalente ao valor da ação executada ( ra'); a execução da obrigação resulta avaliada por (a) mas segundo os valores de (a') ; no conjunto o investimento de (a') resultou compensado.

Na Equação I ( bis), a iniciativa do parceiro não-recíproco (ra') é avaliada por (a) segundo a escala de valores do autor, o que conduz a uma satisfação ou acordo ( sa), e por consequência, à obrigação de (a) manter os valores virtuais em equivalência com o investimento inicial.

Na Equação II (bis), todas as equivalências são mantidas, à exceção da avaliação produzida por (a') que não se satisfaz com a execução das obrigações realizadas por (a) em (ra > sa') mesmo que aquele (a) tenha utilizado o seu ponto de vista (a'); com isso no conjunto a avaliação resulta como perda ou prejuízo com relação ao investimento inicial (sa'< ra').

Se observarmos bem, até aqui, os elementos apresentados correspondem aos de um ciclo solidário inicial, quando a sustentação das ações ainda não produziu um reconhecimento moral nem gerou uma renúncia virtual. Por essa razão, fizemos questão de não introduzir nas equações os termos que lhes corresponderiam (Rm e Rv), para assim tornar mais evidente que seu valor é nenhum (nulo), portanto inócuo em termos dos valores colocados em jogo.

A sequência das trocas, se mantida a sustentação das ações, evidencia o aparecimento de rudimentos de valor moral creditados ao parceiro recíproco. No caso do ciclo solidário, o que devemos ressaltar é a necessidade de uma sequência de ações de sustentação até que o reconhecimento moral se evidencie. É necessário retomar $n$ vezes às iniciativas para que se oportunizem os experimentos solidários que levarão o parceiro não recíproco ao reconhecimento moral. Resumidamente, em termos das equações qualitativas, essas sequências de trocas podem ser colocadas como segue, no início do ciclo solidário: (n vezes) Equação I: (ra > sa'), Equação II: (ra' < sa), satisfação moral de (a). Não há dívida de reconhecimento de a' para com a. (n vezes) Equação I: (ra = sa'), Equação II: (ra = sa), Dívida de reconhecimento de a' para com a ( n vezes) Equação I ( bis): (ra’ = sa), (a) 
valoriza (a') , avalia segundo a escala de valores de (a') ou seu ponto de vista; Equação II ( bis) : (ra = sa'), ( a) executa a obrigação moral segundo a escala de valores de (a') ou seu ponto de vista; Não há dívida de reconhecimento de a para com a'. (n vezes) Equação I (bis): (ra' = sa), Equação II ( bis) : (ra = s a'), dívida de reconhecimento de a para com a'.

As equações qualitativas, a seguir, ainda estão alteradas pelo desequilíbrio nas trocas de valor pois, conforme comentamos, inicialmente apenas um dos parceiros é recíproco ao outro. Entretanto em decorrência da sustentação das ações solidárias, já incluem a presença de a dívida de reconhecimento moral ( $\mathrm{Rm})$ e, igualmente, a renúncia virtual $(\mathrm{Rv})$ que aquela implica:

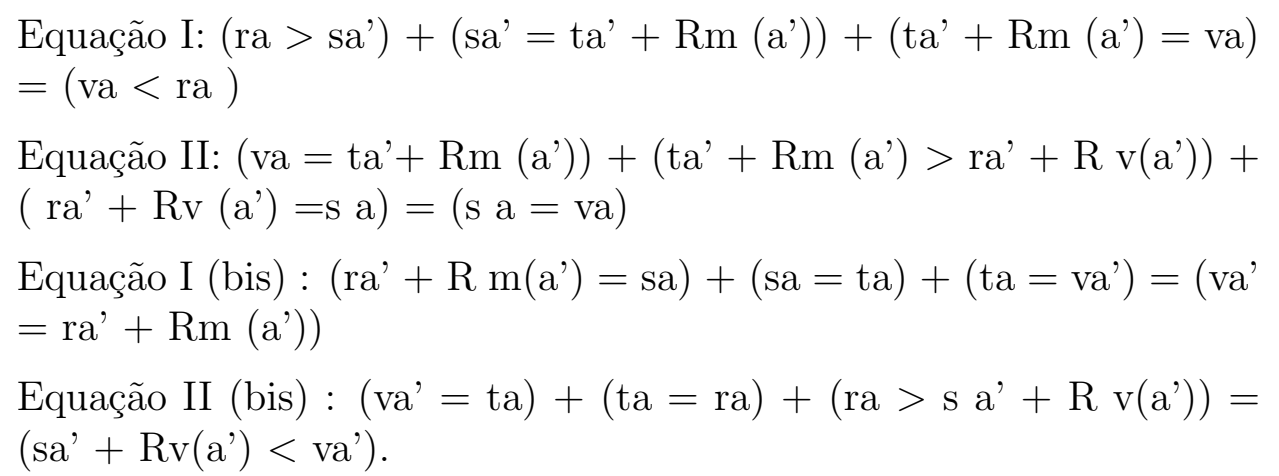

Na Equação I, temos que a satisfação (s a') de (a') equivale a uma obrigação (ta') relativamente à iniciativa de ( a) acrescida pela dívida de reconhecimento moral Rm(va'), se houver; quando (a') reconhece o caráter desinteressado da ação de (a), atribui valor moral ao parceiro (a) e a dívida se transforma numa obrigação moral de (a') para com (a). Na Equação II, temos que a obrigação moral se converte em renúncia virtual $\left(\operatorname{Rv}\left(\mathrm{a}^{\prime}\right)\right)$ e acrescenta valor à execução da obrigação de (a') para com (a).

Na Equação I (bis), temos que a iniciativa de (a') reflete o reconhecimento moral por (a) desde a sua concepção, ou seja, (a') experimenta levar em conta o ponto de vista de (a) e isso significa utilizar sua escala como fruto de uma decisão livre. A incorporação do reconhecimento moral à ação resulta equivalente ao valor virtual da iniciativa, ou seja, a escala de (a) passa a fazer parte do valor de troca de uma ação de (a'). Na

Equação II (bis) temos que a avaliação de (a') sobre a obrigação executada de (a) inclui o reconhecimento do ponto de vista do autor da ação, ou seja, para avaliar a ação de (a), o parceiro (a') livremente utiliza o referencial de (a) e para ( a') isso significa considerar a satisfação de (a) como finalidade de sua ação.

Ao final de uma sequência de trocas no ciclo solidário, a rigor, alcançamos um ciclo cooperativo com reciprocidade mútua entre parceiros. 


\section{A Sustentação Solidária}

A passagem do desequilíbrio para o equilíbrio num sistema de trocas de valores qualitativos é sustentada por coordenação de ações solidárias de um dos parceiros, que denominamos sustentação solidária, até que o sistema alcance, ou o equilíbrio de todas as equivalências (cooperação).

Um sistema de operações que conserva valores morais se carateriza por atender à dupla condição: satisfação indefinida do outro e avaliação segundo a escala do interessado. Ao atender à reciprocidade normativa, isto é, ao aplicar-se aos dois parceiros, torna-se equivalente à substituição recíproca das escalas ou dos meios e dos fins. A possibilidade de descentração aberta pela ação desinteressada do parceiro inicialmente solidário (a), se traduz no outro (a') mediante experimentações concretas, inicialmente isoladas, envolvendo a utilização de escala de valores do benfeitor (a). Essa experimentação ocorre sob a proteção do respeito moral que o parceiro solidário inspira no outro e é por ele sustentada até que as ações de ambos resultem em valores integrados num mesmo sistema operatório.

\section{Considerações Finais}

Ao nascer, os seres humanos não dispõem de estruturas mentais para suportar os mecanismos da lógica das relações, pois as mesmas precisam ser desenvolvidas a partir das interações do indivíduo com o meio. Em função disso, essas interações e, essencialmente, a educação, serão os dispositivos que contribuirão para que os indivíduos e as coletividades venham a desenvolver estruturas mentais cujo funcionamento é capaz de comportar a lógica dos atos cooperativos e solidários.

Por essa razão, a abordagem inicial do tema coloca no horizonte dos desafios e das discussões formuladas pela iniciativa CBS21 a necessidade de se fortalecerem projetos de cooperação entre as duas nações, embasando-o em conhecimentos que podem influenciar positivamente não apenas o convívio e as ações de trabalho inovativo dos participantes, mas também o estabelecimento de marcos educativos relacionados à educação das novas gerações para a cooperação internacional.

\section{Referências Bibliográficas}

Estrázulas, M.B.P.(1997). Interação e Sócio-Cognição na Internet: A Teoria de Desenvolvimento Sócio-Cognitivo de Jean Piaget no estudo das trocas entre crianças na escola e fora da escola. Dissertação de Mestrado, Instituto de Psicologia, Universidade Federal do Rio Grande do Sul, Porto Alegre, RS.

Estrázulas, M.B.P. (2004). Rede JovemPaz: solidariedade a partir da complexidade. Tese de Doudorado, Instituto de Psicologia, Universidade Federal do Rio Grande do Sul, Porto Alegre, RS. 
Freitas, L.L.(1997). A moral na obra de Jean Piaget : um projeto inacabado. Tese de Doutorado, Instituto de Psicologia, Universidade de São Paulo.

Piaget, J. (1973). Estudos Sociológicos. Rio de Janeiro: Forense. Original publicado em 1965.

Piaget, J. (1998). O espírito de solidariedade na criança e a colaboração internacional. Em S. Parrat-Dayan \& A .Thryphon, (Orgs.) Jean Piaget: Sobre a pedagogia. (pp. 59-78) São Paulo: Casa do Psicólogo. Original publicado em 1931.

Recife, Olinda, Maceió, 2014 